\title{
How farmers think about insects: perceptions of biodiversity, biodiversity loss and attitudes towards insect-friendly farming practices
}

\author{
Maria Busse $^{1}$ (D) $\cdot$ Felix Zoll ${ }^{1} \cdot$ Rosemarie Siebert $^{1} \cdot$ Annette Bartels $^{2}$. \\ Anke Bokelmann ${ }^{2} \cdot$ Phillipp Scharschmidt ${ }^{1}$
}

Received: 24 August 2020 / Revised: 23 June 2021 / Accepted: 28 June 2021 /

Published online: 19 July 2021

(c) The Author(s) 2021

\begin{abstract}
An alarming decrease of insects in number and variety calls for measures of protection and promotion, since insects are crucial for the functioning of ecosystems and provide multiple ecosystem services. Agricultural landscapes can provide vast insect habitats if they are managed accordingly. However, little is known about farmers' problem awareness and attitudes toward insect biodiversity loss, related farming practises, or alternative acceptable insect-friendly solutions. To fill these research gaps, this paper aimed to reveal farmers' perceptions and attitudes regarding these aspects in two German case studies. We conducted 23 semi-structured interviews with farmers in 2019 and qualitatively analysed them using semantic web analysis. Farmers mostly reported awareness of insects' ecosystem services and disservices related to agricultural production rather than mentioning the holistic ecological importance of insects. About half of the farmers confirmed insect loss based on their own observations, whereas a similar number doubted there had been a decrease of insects. Most farmers are open-minded towards insect-friendly measures if financially compensated. The farmers also mentioned a joint societal responsibility for insects, economic pressure on farmers to use pesticides due to global market prices, and unbalanced agricultural policies. This study revealed in-depth insights into farmers' thinking about insects and how farmers contextualise arguments. Our results identified overlaps in farmers' mental models, which paves the way for co-designing insect-friendly farming practices in landscape labs. Local transformation efforts can also demonstrate new pathways for a shift on the higher levels.
\end{abstract}

Keywords Landscape labs · Agricultural system - Ecosystem services · Mental models · Socio-cultural values $\cdot$ Lock-in effects

Communicated by Eckehard G. Brockerhoff.

This article belongs to the Topical Collection: Biodiversity appreciation and engagement.

Maria Busse

maria.busse@zalf.de

Extended author information available on the last page of the article 


\section{Introduction}

Insects play a crucial role for ecosystem functioning in general and in agricultural landscapes in particular. As major contributors to species richness and biotic biomass on earth, insects are an integral component for maintaining nested natural networks and food webs, e.g. by being food source for other organisms (birds, amphibians, and mammals) (Jankielsohn 2018). Insects deliver irreplaceable ecosystem services, such as pollination, natural pest control, decomposition of organic matter in soils or seed dispersal - which are also important for agricultural production (Isaacs et al. 2009; Schowalter et al. 2018; Dainese et al. 2019; Cardoso et al. 2020). However, insects have been decreasing in both numbers and variety in the last decades. Intensification and simplification processes in agricultural landscapes and associated practices such as the use of agro-chemicals and pesticides, the deterioration of water bodies through fertilization, and frequent and homogeneous cutting of grasslands, which removes the floral food sources of insects, results in a loss of habitats for insects and numerous other species (Potts et al. 2009; Grass et al. 2016). The loss of insect abundance and biomass causes a decrease of numerous ecological functions and ecosystem services provided by insects with far-reaching negative consequences for biodiversity, complex biotic interactions, and also human wellbeing (Dainese et al. 2019). Negative ecological consequences include disturbances in trophic networks, extinction of endemic species, and higher exposure to vulnerability to secondary extinctions in ecosystems (Gordon et al. 2019). Economic and ecological consequences can result from a reduced performance of pollinators and insect antagonists of pests, which in turn could lead to yield losses and lower agri-food production outputs (Cardoso et al. 2020). Even cultural ecosystem services can be compromised, such as nature tourism specialized on attractive "flagship" insect species, connectedness with nature, or cultural heritage based on endemic insects (Cardoso et al. 2020; Hall and Martins 2020).

Agricultural landscapes, which cover more than half of our planet's surface, can provide vast insect habitats if they are managed accordingly. So far, there is a lack of implemented insect-friendly farming systems, which calls for the development of suitable solutions (Samways et al. 2020). However, little is known about farmers' perspectives concerning their awareness of the problem and their attitudes towards the insect biodiversity decrease, current farming practises or alternative acceptable solutions. Noting that farmers' land management decisions have an enormous influence on biodiversity (Kelemen et al. 2013), their perspectives (in terms of perception, motivations, attitudes, etc.) should be considered when developing solutions. Generally, the involvement of local actors is needed to legitimize decisions (Reed et al. 2009) and also to generate place-based, applicable, and acceptable solutions (Lange et al. 2016; Zscheischler et al. 2017; Campellone et al. 2018).

Screening the literature on farmers' perception of insect biodiversity (search terms 'farmer' + 'perception' + 'insect') from the last 10 years in the SCOPUS database yielded 49 studies with diverse topics. Most often articles (35) about particular pests in cropping systems were published, mainly reporting case study areas in Africa. Nine publications from all world regions are dedicated more generally to farming management regarding insects. Regarding farmers' knowledge and perception of and attitudes towards beneficial insects, studies about natural pest control by parasitoids (Salliou and Barnaud 2017; Bardenhagen et al. 2020; Martínez-Sastre et al. 2020) and pollinators (Tarakini et al. 2020; Hevia et al. 2020) predominate. Whereas studies about pollination services also consider flowering crops other than fruit-bearing plants, studies on natural pest management refer only to orcharding but not to arable land use or mixed farming. There is also a need for 
Table 1 Cultivated crops between 2015 and 2019 in \% per case study area

\begin{tabular}{lcc}
\hline Cultivated crops & $\begin{array}{l}\text { Landscape lab } \\
1(\%)\end{array}$ & $\begin{array}{l}\text { Landscape } \\
\text { lab 2 (\%) }\end{array}$ \\
\hline Wheat [Triticum aestivum] & 44 & 15 \\
Barley [Hordeum vulgare] & 14 & 14 \\
Maize [Zea mays] & 11 & 32 \\
Rapeseed [Brassia napus] & 15 & 12 \\
Sugar beets [Beta vulgaris] & 6 & 0 \\
Alfalfa [Medicago sativa] & 0 & 16 \\
Other crops & 10 & 11 \\
Total & 100 & 100 \\
\hline
\end{tabular}

more holistic studies which are open for farmers' perceptions of diverse ES, disservices (EDS), and ecological functions of insects. Until now, the awareness and understanding of the insect biodiversity loss has been only addressed in the recent study by Hevia et al. 2020. Undoubtedly, this issue needs more attention in the scientific literature because farmers' problem awareness is an important precondition for transformative actions toward more insect-friendly farming practices.

To fill the research gaps identified above, this paper aimed to reveal farmers' perceptions and attitudes in the form of mental models regarding insect biodiversity in two German case studies. More specifically, the paper addresses the following questions:

1. How do farmers perceive insect biodiversity and the insect biodiversity loss?

2. What are farmers' attitudes toward insect-friendly farming measures?

3. How do farmers contextualize their perceptions and attitudes in terms of farming practices, societal values, and political-economical systemic aspects?

\section{Materials and methods}

\section{Case study regions and data collection (semi-structured interviews)}

We conducted our research in two case study regions in northern Germany. In the case study regions we established so-called "landscape labs", each covering a landscape section of 3 by $3 \mathrm{~km}$, i.e., 900 ha (Fig. 1). The first landscape lab is located in the Federal State of Lower Saxony. Here, 613 ha of the 900 ha are used by agriculture. The production focus is on crops (488 ha), especially wheat, and only to a marginal extent on grassland (125 ha). The average farm size is 180 ha, whereas the single plots are between 1 and 10 ha. In the context of the German farm structure, these farms and plots can be considered as medium-sized. The second landscape lab is located in the northern part of the Federal State of Brandenburg. The region is characterized by a high contiguous grassland complex that is used by farmers for livestock farming and for biogas production, with 445 ha of the 778 ha of the agricultural area consisting of grassland. However, crops are also produced to a considerable extent (333 ha). Farmers produce mainly maize, wheat, barley, alfalfa, and rapeseed (Table 1). In landscape lab 2, the farms vary in size between 31 and 1460 ha. The farm plots comprise about 15-20 ha. 


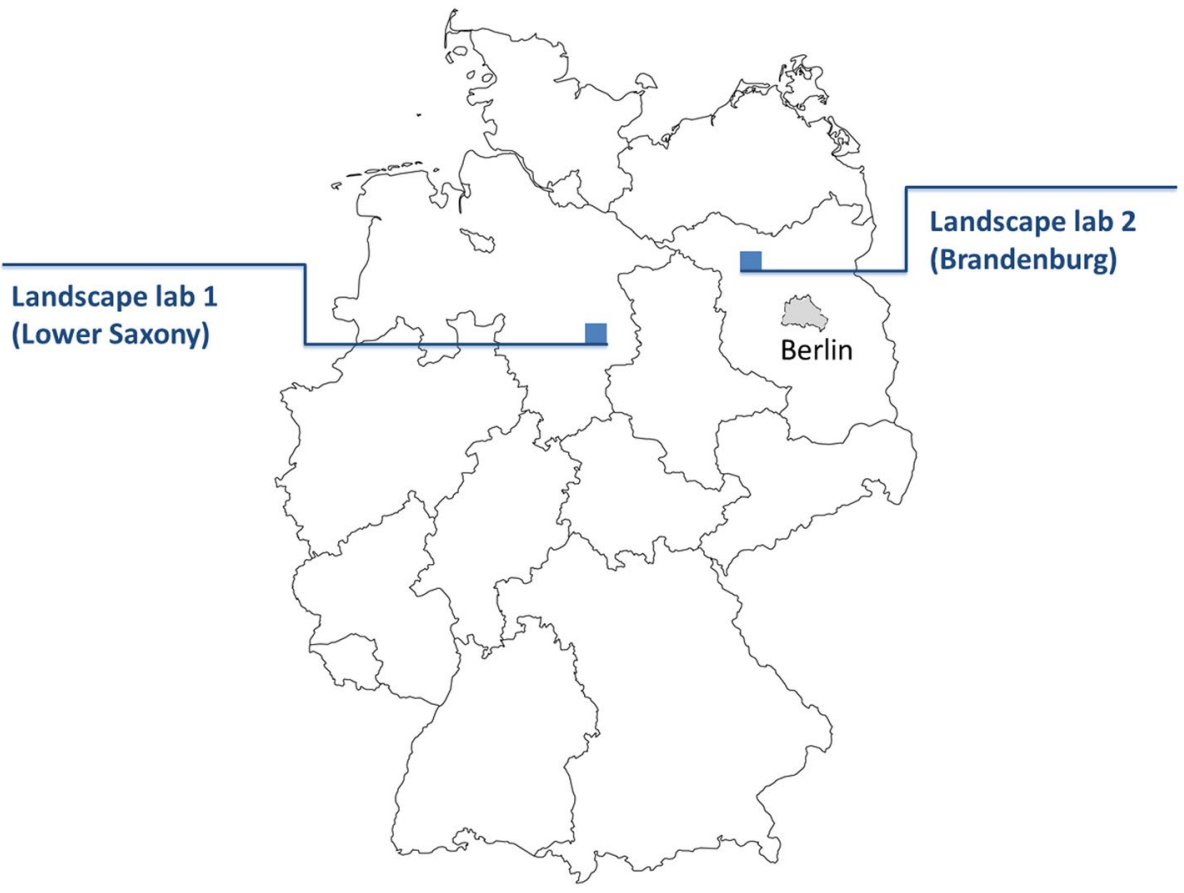

Fig. 1 The location of the two case study regions (landscape labs) in Germany

To reveal the perception and attitudes of farmers we applied an explorative and qualitative research approach, which is mentioned in the literature as being suitable for exploring complex real-life phenomena where many aspects are still unknown (Patton 2019). We used semi-structured and problem-centred interviews as data collection method (Witzel 2000). A total of 23 interviews with local farmers were conducted in the two case study regions from 2019 to 2020 . We requested interviews with all farmers who have land plots in the boundaries of the landscape labs. In landscape lab 1, we interviewed 19 of 24 farmers, and 4 of 8 farmers in landscape lab 2. All interviewees cultivate their arable land conventionally. Additionally, two farmers, one in each landscape lab, manage their grasslands ecologically.

Interviews were conducted face-to-face, and each lasted between $30 \mathrm{~min}$ and one hour. We used an interview guideline that encompassed questions about the farm's management, individual meanings of insect biodiversity and insect biodiversity loss, general farming practices and existing insect-friendly measures, and the attitudes towards introducing new insect-friendly farming measures (see annex 1). To meet the requirements of transparency and reliability in qualitative research (Patton 2019), we produced interview notes, which included the personal impressions and circumstances of the interview situation, as well as additional information beyond the recorded interview itself. The audio-recorded interviews were transcribed. Afterward, the transcripts were sent to the interviewees, thus providing them with copies with which to confirm the interview content. This procedure follows the ethical standards of qualitative social science (Mero-Jaffe 2011). 


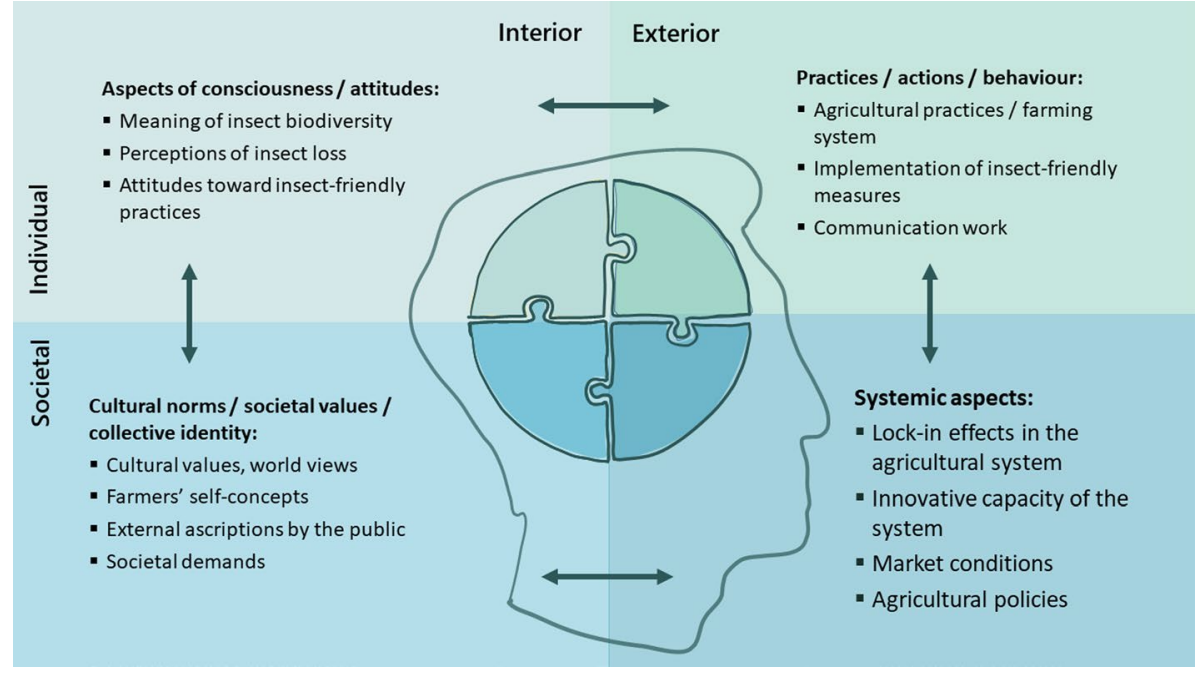

Fig. 2 Analytical framework that includes four dimensions/quadrants: the individual-interior, individualexterior, societal-interior, and societal-exterior. Each quadrant focusses on specific aspects as the examples show in the figure (own compilation using the four quadrants framework of integral ecology, adapted from Esbjörn-Hargens and Zimmerman 2009; Zylstra et al. 2019)

\section{Analytical framework (as a base map for semantic web analysis)}

Considering and integrating different perspectives on social-ecological systems and the respective human-nature relationship is essential to reveal the complexity of real-world issues (Esbjörn-Hargens and Zimmerman 2009; Zylstra et al. 2019). Social-ecological systems can be understood as intertwined and adaptive systems in which social and ecological subsystems relate to each other and are interdependent in mutual ways (Berkes 2017).

Often researchers analyse complex phenomena through disciplinary lenses, sticking to certain theories or epistemologies and adopting a limited perspective. For example, environmental psychology focusses on individual aspects by showing how values and attitudes of individuals affect their behaviour (cf. Kelemen et al. 2013). Behavioural economics studies also use an individual and utilitarian perspective where individual economic values (individual utility maximization) are in the foreground. Political studies are specialized in understanding socio-political framings, system structures, institutional settings, and legislation, but focus less on considering individual perceptions or societal and cultural values. To avoid analyses from a limited perspective and to work towards unifying different disciplinary perspectives on social-ecological phenomena, a framework of four dimensions has been proposed by the integral ecologists Esbjörn-Hargens and Zimmerman (2009): The individual-interior dimension illustrates thoughts, perceptions, and attitudes of a person. The individual-exterior dimension provides information on person's actions and practices based on their inner convictions and thoughts. The societal-interior dimension refers to cultural values in the society, self-concepts of groups, external ascriptions by the public or societal demands. And the fourth, the societal-exterior dimension, reflects the systemic perspective and includes considerations on market conditions, policies or lock-in effects (Fig. 2). All dimensions are intertwined, and the boundaries between them are rather blurry than sharply delimited. 
Using this framework supports a holistic view and enabled us to elicit farmers' complex considerations on insect biodiversity and insect loss. Based on other research and after conducting our interviews, it became clear that farmers contextualize their perceptions of socio-ecological phenomena, such as insect biodiversity (loss) and attitudes toward insectfriendly measures by referring to systemic aspects, cultural norms and societal values (cf. semantic web analysis). We combined the four-quadrant framework with the method of web diagrams to display the mental structures and reasoning of farmers.

\section{Data analysis procedure (semantic web analysis)}

Our study is epistemologically based on subjectivism which assumes that each subject imposes individual meaning to objects and, thus, various realities can co-exist (Moon et al. 2019). With our analysis we conduct interpretive research gaining insights into social realities and the construction of meanings through an interpretive understanding of documented statements. To interpret the semi-structured interviews, we used the semantic web analysis described in Wood et al. (2012) and Prager and Curfs (2016). The semantic web analysis is a scientific method of analysing and displaying actors' mental models in so-called web diagrams using qualitative data (e.g., semi-structured interviews) (Wood et al. 2012). Mental models are internal representations and cognitive frameworks of how people understand the world or specific external issues on the basis of filtering incoming information (Biggs et al. 2011; Wood et al. 2012).

Mental models are thinking patterns of people that reflect their perceptions, values, beliefs, motivations, or attitudes, which are also linked to actions, practices and behaviour (Wood et al. 2012; Prager and Curfs 2016). Semantic web analysis is one possibility of scientifically conceptualising mental models and displaying them in network maps. In contrast to other methods semantic web analysis does not rely on computer models and quantification (Wood et al. 2012). Mental model techniques are applied in different disciplines and research fields such as psychology, sociology, spatial planning, and organisational research (Biggs et al. 2011; Prager and Curfs 2016). However, what they all have in common is that they are models of people's mental structures that have been translated into conceptual interlinked systems. Thus, the use of mental models techniques facilitates system thinking, sheds light on different perspectives on an issue, offers the possibility to derive suitable solutions, and supports decision-making for innovation processes by revealing the shared and complementary views of the actors (Biggs et al. 2011; Prager and Curfs 2016; van Hulst et al. 2020). Applying a qualitative mental model technique can reveal deep insights into the thinking of people and allow for comparisons of their individual patterns by displaying overlaps and divergences (van Hulst et al. 2020). Generally, semantic web diagrams illustrate mental structures in the form of complex and relational networks, which consist of nodes and arrows or connecting lines. The nodes represent the concepts (mostly in the form of nouns). The arrows or lines connect the nodes and are associations between the concepts, which are often labelled with relationship terms (mostly in the form of verbs) (Wood et al. 2012).

Our procedure of analysis consisted of the following steps:

a. We used the transcriptions of the interviews to scan and choose meaningful statements in the form of original quotations on insect biodiversity, biodiversity loss, insectfriendly farming practices and context factors. This qualitative analytical step is based on researchers' interpretations (Patton 2019). 


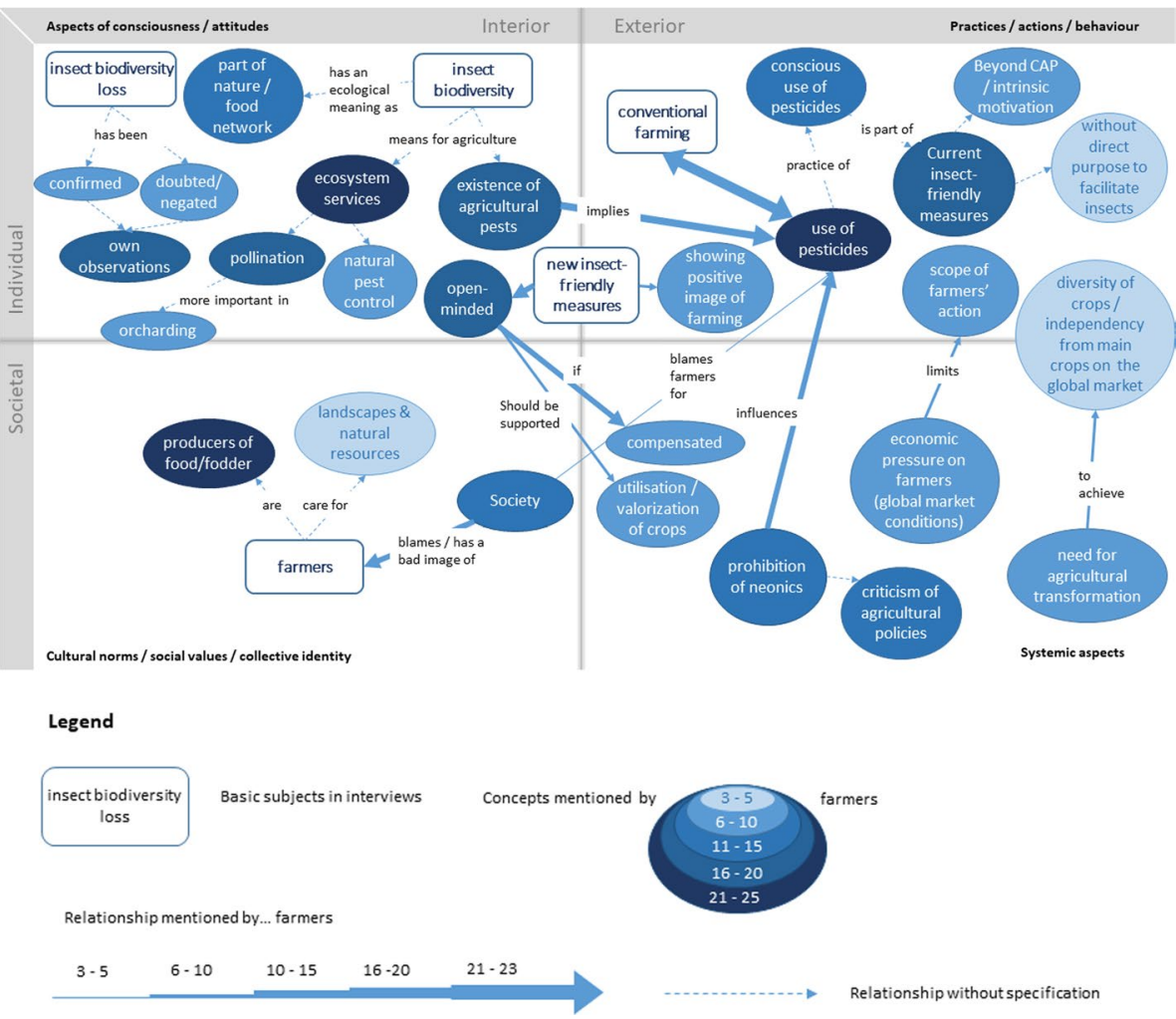

Fig. 3 Grouped web diagram of the farmers' mental model on the basis of all 23 interviews. The degree of overlap is displayed by the colour of the concept nodes and the thickness of the relationship arrows. The darker the blue the more farmers mentioned the issue (see legend)

b. In the next step, we sorted the quotations from each interview into a separate four quadrants diagram (the four quadrants framework is described below) and added a short interpretation of each quotation.

c. Afterward, we summarized the quotations and converted the summaries into abstract concepts. Such a process of reducing the text complexity is typical for qualitative text analysis (Kuckartz 2014; Mayring 2014). The abstract concepts were integrated into the semantic web diagrams with nodes and arrows by using the four quadrants as a basis map. The outcome is a combination of a semantic web diagram and a four quadrants diagram. We elaborated on the individual web diagrams for each interview (see annex 2).

d. In an intermediate step of analysis, we generated a grouped web diagram for landscape lab 1 (19 cases) and one for landscape lab 2 (4 cases).

e. In the last step, we merged all of the individual diagrams into one grouped diagram by illustrating overlapping concepts and relations (cf. Moon et al. 2019). The most commonly mentioned concepts and relationships of the interviews are displayed using different colours for the concept nodes and varying the thickness of the relation arrows to indicate the degree of overlaps in the concepts and relationships (see Fig. 3). To build 
the group map, we discarded concepts which were mentioned by less than five farmers (corresponding to a $20 \%$ threshold).

f. All analytical steps were checked by the second author to secure the quality of the analysis and to avoid subjective bias (Kuckartz 2014; Mayring 2014).

\section{Results}

When comparing the group diagrams of landscape lab 1 and 2, it turned out that farmers' mental models have many overlaps in their fundamental structure. These overlaps can be explained by the common practices in conventional agriculture (e.g. use of pesticides), socio-political framing conditions, societal demands, public debates about insect conservations, and shared farmers' self-concepts which play a more important role throughout Germany than regional differences (e.g., farm size, biotic and abiotic landscape factors). The main outcome of our sematic web analysis is the group diagram of all farmers which depicts most frequent overlapping concepts and relationships (Fig. 3). The group diagram shows also how many farmers support or do not support the particular concepts. In the following, we describe the content of Fig. 3 stepwise per quadrant. It is important to note that the quadrants should be understood as dynamic, interacting, and having fluent crossovers.

\section{Individual- interior dimension}

\section{Importance of insect biodiversity}

When farmers were asked about their perception of insect biodiversity, all of them emphasised the importance of insect biodiversity for human purposes such as farming. The farmers clearly differentiated between beneficial insects which supply ecosystem services (ES), and harmful insects which bring about ecosystem disservices (EDS). Although farmers did not use directly the terms "ecosystem services" or "disservices", we classified the corresponding statements as ES and EDS. In the context of ES, pollination was mentioned more often (17 farmers) than natural pest control by insect parasitoids such as ladybirds or hover flies (9 farmers). However, there were diverging statements regarding to which extent pollination is important for the interviewees' farm operations. Of all the main crops in the case study regions (see Table 1), only rapeseed (Brassica napus) depends on pollinator insects. However, rapeseed is only cultivated on $15 \%$ of the arable land in case study area 1 , and accounts for $12 \%$ in case study area 2 . Thus, six farmers mentioned that pollination would have greater importance in orcharding because fruit trees need pollinators for fructification. Regarding natural pest control, two farmers mentioned that it is difficult for them to observe the direct impact of beneficial insects on their yield results.

Well, without insects there is no pollination and without pollination I obviously will not be able to harvest rape. Wheat and barley are self-pollinating, I think. But it is not just that_-The whole orcharding sector [does not work] without insects (Farmer 8).

Regarding EDS, the vast majority of farmers (19) mentioned that their agricultural activities are affected by agricultural pests through harmful insects (mostly aphids, corn borer [Ostrinia nubilalis], rape pollen beetle [Brassicogethes aeneus]). Other supporting ES, such as the decomposition services and seed dispersal by insects, were not mentioned by 
any farmer. About half of the farmers (12) stated other values of insects beyond agricultural ES and EDS, which included insects' ecological importance as nutrition for other species (mainly birds were mentioned) and as crucial part of the whole ecological system. Farmers who associated the importance of insects directly to specific beneficial species (or groups of insects) almost always referred to the honeybee [Apis mellifera] (5 farmers) and seldom to ladybirds.

\section{Perception of insect biodiversity loss}

The majority of farmers is currently aware of the insect biodiversity topic due to extensive media coverage and political discussions in the last two years. Farmers' judgments on insect biodiversity loss are mostly based on their own observations and experiences on their farms and in their regions rather than on other information sources. Only one farmer referred generally to scientific evidence when confirming the decrease of insects from their own perspective, though without mentioning a specific study. Regarding the question, if we indeed face a strong decline in insect biodiversity (as noted by scientists, politicians, and media), the farmers' opinions differed, sometimes substantially. Nine farmers confirmed having perceived an insect biodiversity loss, whereas the similar number of farmers (9) doubted or clearly negated the decrease of insects. Only two farmers stated that they were not able to assess biodiversity because of a lack of knowledge. The remaining three farmers stated that they did not think about the issue or that it has not played an important role yet.

There has been a decrease [in insects], just considering that we have much less flies here, which is also a result of the general restructuring of farms. There is rarely any animal husbandry anymore, all the dung heaps have disappeared. As a result, there is a lack of food sources for other insects and birds that we have as well (Farmer 4).

I have not noticed yet that there are too few insects. [...] My sugar beets and my wheat is also full of aphids and wheat midges and all that. Maybe that is climatedependent if it is dry all the time, insects struggle as well, just like last year. And if this year is warm and humid, it might be a bit better for the insects. And the year before we had enough insects as well, back then, my car was plastered with insects. But maybe it is also a political topic. Everyone is attracted to it (Farmer 14 from same region as farmer 4).

\section{Openness to new insect-friendly measures}

Asked about their attitudes towards experimenting with new farming measures that could facilitate insects, most farmers (18) were open-minded. However, it became clear that they will not perform insect-friendly measures just for a good cause and due to an intrinsic value of insects (inherent moral value for being valued for their own sake beyond human needs and values). Most farmers stated that they would try out measures if there was a financial compensation such as project funding, AEM or additional payments supported by the society (10 farmers) or a sufficient profitability of the yield in terms of a favourable use on the own farm or as income-generating product on the market ( 7 farmers). Concerning the latter, farmers mentioned that if alternative crops are grown as a measure to increase insect biodiversity (e.g., flowering energy crops), there has to be a demand and a value chain utilizing the produced crops. Beyond the economic aspects, the farmers stated that performing insect-friendly measures is an opportunity to show a more positive image of 
farmers to locals and the public. However, five farmers were more sceptical and stated that they would not perform insect-friendly measures.

Well, it is always beneficial, if you could grow grass or do something positive [for insects]. It is not just me but other farmers are certainly also willing to do something [and] if it is subsidised accordingly. There always has to be a conformity, the agricultural sector has to live and survive as well (Farmer 21).

\section{Societal-interior dimension}

\section{Farmers' self-identifications}

In the very first place, the farmers see themselves as producers of food and fodder (19 farmers). This collective or group identity was visible through clear statements such as: "I don't want to work merely as a landscape caretaker. I became a farmer to cultivate products ready for the market" (Farmer 10) or more implicitly through the stated wish to generate a product instead of cultivating only plants for insects and destroying them afterward (e.g., Farmer 4). Assuring production quantity and quality is their first aim; and the attached importance of profitability is strongly related to this thinking.

Five interviewees stated that farmers generally are per se caring for their landscapes and the regional natural resources. They consider themselves as supporters or conservers but not as destroyers of nature.

We ourselves or the farmers in particular are actually also very close to nature and we also want that there are more insects (Farmer 15).

\section{Perceived view of the society on farmers}

Often farmers mentioned in the interviews that society would blame them for the decrease of insects, biodiversity loss in general, and the abusive use of pesticides. Generally, farmers do not want to be accused of being the sole culprits in the debate on declining insect biodiversity. Interviewees advocated that the issue should be treated in a holistic manner, where multiple causes, such as light pollution, are considered as well. Ten farmers complained about the bad image of farmers in the public mind and felt unfairly treated by society and politicians. The interviewees felt misunderstood by non-farmers (labelled as the society or the people) because society does not have a realistic picture of agriculture, especially the urban population and "the Greens". The term "the Greens" was used by two farmers to refer generally to various groups such as the Green party or environmentally minded people. Additionally, the media is perceived to fuel the discussions by overstating and one-sided reporting that farmers are "bad". Five farmers commented on the contradictory behaviour of consumers. The people demand nature conservation while they are not willing to pay more for environmentally friendly food production.

Of course the farmers are missing a bit of recognition. That used to be different. [...] Back in the days, the farmer was responsible for the production of food and for the preservation of mankind [...]. In my opinion, there is no real appreciation for what we provide to the world (Farmer 18).

We are the farmers without a face. There are only discussions on glyphosate, dying bees and such things. People observe farmers driving by with a crop protection 
sprayer and say: "Look, he is spraying poison again". They have no idea what we are doing there. We might as well spray fertilizer (Farmer 23).

\section{Individual-exterior dimension}

\section{Conventional farming and the use of pesticides}

All interviewed farmers cultivate their arable land conventionally. Two farmers are additionally managers of a second farming business with ecological grassland cultivation. A general result is that conventional farming and the utilization of pesticides are interlinked. The conventional farmers make use of their right to utilize pesticides under existing agricultural regulations. According to them, spraying is a necessary practice to protect the crops and assure their yields, and this is the only way to cultivate economically. As already pointed out above, farmers very often mentioned having problems with agricultural pests and weeds. Therefore, almost all of them (22 Farmers) brought up the topic of using pesticides when asked about the meaning of insects for agriculture. Eleven interviewed farmers mentioned that they use fewer pesticides if possible, exhibiting consideration for insects, e.g., they usually waive an insecticide treatment in the flowering phase of rapeseed, or they spray only at night to save pollinators and other insects.

It is a tool [glyphosat] and we need that tool. We cannot send a plumber out without a pipe wrench. It does not work (Farmer 16).

You do not spray just like that, you also check if there actually are [harmful] insects and if they are there, you simply have to do something about it (Farmer 13).

\section{Applied insect-friendly measures by farmers}

Nineteen farmers stated that they already perform some insect-friendly measures. They mentioned practices such as flowering strips/areas or honey fallows, which are compensated through the "greening bonus" or agri-environmental schemes (AEMs) within the Common Agricultural Policies (CAP) of the European Commission. Sometimes farmers thought that they did not perform such measures yet. During the interviews, it turned out that indeed they do but without considering these measures as supportive for insects. These measures include flowering catch cropping (faba bean [Vicia faba] or pea [Pisum sativum]) and hedgerows. Catch cropping is mainly seen as a soil conservation measure and is not directly aimed at/tailored to insects. Similarly, hedgerows serve in the first place to stop wind erosion. Eight of the interviewed farmers perform more extensive insect-friendly measures than those compensated by the Common Agricultural Policies (CAP), e.g., big field plots with honey flowers or planting new hedgerows.

\section{Societal-exterior dimension}

\section{Prohibition of neonicotinoids—short "neonics" (and other pesticides)}

When talking about agricultural pests and the use of pesticides, thirteen interviewed farmers complained about the recent prohibition of the insecticides group of neonics by the European Commission. The seed treatments of sugar beets and rapeseed with neonics was 
a common practice to control most insect pests. The prohibition necessitates a different pesticide treatment of the crops. Farmers are now concerned that they have to spray both more often and in a more extensive area, which seems to them to be more costly and harmful for insects. Current debates on the ban of glyphosate in EU countries was also a point of concern in seven interviews, because they felt restricted in their scope of action and see glyphosate as just as essential for cultivating economically as the neonics.

I'm bringing out pyrethroids now. Every beneficial insect that is there then, actually working in my favour, I have to kill as well, unfortunately. Before, that had never been the case. Before, small doses [of neonicotinoids] were applied to the seeds, professionally. But you just have to see it that way that from my point of view, the situation for insects has worsened in this respect. Because around the neonicotinoids there really is hysteria (Farmer 10).

\section{Unbalanced agricultural policies}

Eleven of the interviewed farmers refered to agricultural policies, mainly AEMs. Concerns were mentioned about the fitting of regulations into regional conditions and the different interpretations/implementation of regulations in the EU. Interviewees lamented that farmers in Germany are more strictly controlled in following the regulations than in other European countries. Additionally, on a global level, farmers identified diverging standards on the sustainability of agricultural production.

It is [politically] preferred that the rain forest is cleared. Every year a few thousand hectares. But we still have to sign a self-declaration that we are not going to plant our renewable resources on ploughed grassland by no means. It makes me sick to my stomach, every time. But the rain forest may just disappear (Farmer 12).

\section{Economic pressure}

A considerable number of interviewees (9 Farmers) stated that farmers' business depended on global markets, especially regarding their main crops. They commented that the production conditions in their regions were less favourable than in other world regions with huge and homogeneous farm plots and less environmental requirements. The immense competition on an international market places pressure on German farmers, which leads to a limited scope of action (including the limited possibility of performing environmental-friendly farming and reducing spraying). Additionally, insect-friendly crops (e.g., flowering crops) are not a main crop from which farmers can generate considerable incomes. In both case study regions, there is a lack of adequate value chains for alternative products (e.g., alfalfa, sunflower, faba beans, hemp) that would diversify farm production. Therefore, seven farmers see the need for a transformation in agriculture and the chance to become more independent from global markets by establishing alternative value chains for alternative/ regional value products.

It is critically that profitability still plays a decisive role. Leasing prices are high, fertilizer prices are high and no farmer can afford to harvest less from their plots under these conditions. If growing crops for biogas plants becomes more interesting and the profit is appropriate, then, many farmers will rethink their position, in my opinion (Farmer 18). 
You have to cultivate diversely; it does not work any other way today. But there has to be a market and there has to be a profit in the end. Farmers are totally constricted. The global market puts a lot of pressure on us (Farmer 19).

\section{Discussion}

In accordance with the results section, we have structured the discussion section according to the four quadrants scheme. Nevertheless, the arguments in each quadrant are highly interwoven with the arguments in other quadrants. Thus, some issues could be discussed in more than one quadrant.

\section{Individual- interior dimension}

Our results show that farmers use different narratives about biodiversity and arguments for or against conserving biodiversity. Bardsley et al. (2019) conceptualized seven different narratives on biodiversity on the basis of interviews with Australian farmers: (1) biodiversity for natural habitats, (2) biodiversity for resource management, (3) biodiversity for agricultural pests and weed suppression, (4) biodiversity to define the regional aesthetics, (5) holistic values of biodiversity, (6) biodiversity for production resilience, and (7) biodiversity to improve marketing opportunities. Some of these narratives can be aligned as well to the statements of the interviewed farmers on insect biodiversity. Especially, biodiversity for agricultural pests by reducing damages of crops through beneficial insects was mentioned as important. Additionally, the holistic value of biodiversity was considered by some farmers in our study when stating that they live in a diverse and well-structured cultural landscape where the insect biodiversity loss is less of a problem than in agricultural regions mainly based on big field plots and monocultures. Finally, the last narrative, "biodiversity to improve marketing opportunities", played a role for the interviewed farmers in the sense of realizing the need to establish a broader crop diversity to protect insects and as an opportunity to create regional value chains.

Not only our interviewed farmers attribute a particular status to honeybees, but other studies also revealed that honeybees are the most prominent representative for bee diversity and pollinators among most human populations (Leandro and Jay-Robert 2019; Hall and Martins 2020). The reasons for this might be the long tradition of honeybee 'domestication' and benefiting from their products (e.g., honey or royal jelly) and pollination services in orcharding. These well-perceived benefits lead to a positive image, and accordingly, they are a so-called 'flagship species': People have a special appreciation of honeybees and consider them to be worthy of protection (Leandro and Jay-Robert 2019; Hall and Martins 2020). At the same time, some of the interviewed farmers admitted to knowing much less about other insect species, except for harmful insects. This is also in line with the state-of-the-art regarding insect research (Hall and Martins 2020). The emphasis on honeybees as a representative for a vast species diversity of pollinators carries some risks. (1) Wild insect species are marginalized regarding people's conservation efforts. (2) A disproportional attention to honey bees can lead to a poor understanding of the needs of nonmanaged insect species in terms of habitat, nutrition, as well as their reproduction and the importance in complex ecosystems (Hall and Martins 2020). The diversity of values held by insects is often unknown to people and should be comprehensively communicated for better conservation of insects in the future (Samways et al. 2020). Our results and previous 
discussion uncover that farmers mainly hold an anthropocentric view on insect biodiversity. In the context of our study, anthropocentric view means that farmers refer to human interests only (insect-related ecosystem services and disservices) but do not value insects intrinsically for their own sake as living beings. Conservationists base their reasoning often on inherent moral values of biodiversity and landscapes without considering that land users rely more on values that support people's needs and well-being (Busse et al. 2019). Our recommendation is to openly discuss these different values among stakeholders (farmers, land users, conservationists, citizen, and policy decision makers) and scientists to subsequently identify joint values and conservation aims for collaborative actions.

Kelemen et al. (2013) revealed that European farmers' perceptions of biodiversity are strongly embedded in their everyday lives and linked to their farming practices. This statement is supported by our results about the perception of whether the world is confronting a decline in insect biodiversity or not. Most of the interviewed farmers confirmed, doubted, or even negated insect biodiversity loss by relating to their own judgments, observations and regional aspects. Questioning insect biodiversity loss and the responsibility of agriculture for this phenomenon can be explained by feeling blamed and less respected by society (for further details see Sect. Societal-interior dimension).

Our interviews showed that many farmers are generally open-minded but need financial compensation for insect-friendly measures. Often they stated that they would do more, but this has to be appreciated by society (see also Sect. Societal-interior dimension). Studies on the willingness of farmers to adopt innovative and sustainable farming practices (such as using agricultural by-products as feedstock for generating bioenergy) showed that openness to change, farmers' self-concepts, and internal ecological worldviews are important factors that influence the farmers' acceptability (Warren et al. 2016; Wensing et al. 2019).

\section{Societal-interior dimension}

Farmers' self-concepts are still dominated by production-oriented identities (Burton and Wilson 2006; Warren et al. 2016). This narrative stems from the post second-world-war time when food sovereignty played the most important role in society (Mills et al. 2017). For farmers who stick to this narrative, productivity has priority over nature conservation, and they feel obliged to produce as much and best as possible (Mills et al. 2017). Additionally, the thesis that a productive farm is an important status achievement for some farmers and that their productivity efforts should be adequately recognized and appreciated by others (Mills et al. 2017) can be confirmed by our interviews. From psychological studies, it is well-known that positive judgments by others and feeling respected supports the self-image of people, including farmers (Mills et al. 2017).

Within the last few decades, societal values in Europe and the Global North have been changing. More sustainable food production is demanded by a larger proportion of people, and issues such as animal welfare and biodiversity conservation have become increasingly more important to people (Benard and de Cock Buning 2013; Hatt et al. 2016). For two years, the decline in insect biodiversity has attracted broad media attention and considerable public interest, which is reflected in the wide media coverage and an increasing number of scientific articles, petitions and political decisions. In Germany, two regional public referenda have been carried out by non-governmental nature conservation organisations in 
2019: in the Federal State Bavaria, the referendum 'Save the bees' ${ }^{1}$ and in the Federal State

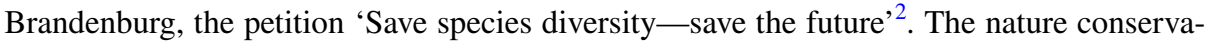
tion organisations of Lower Saxony-the federal state where our case study region 1 is located-followed this pathway, and started a referendum in $2020 .{ }^{3}$ These new demands reach farmers, and the success of the petitions put them under even more pressure. They have to deal with changing societal values and demands but often still feel committed to the 'old' value paradigm of productivity. This tension between society and farmers leads to protests and negative reactions. For instance, a farmers' organisation launched an alternative petition for protecting insects ('Protect insects—-preserve cultural landscapes') ${ }^{4}$ in the Federal State Brandenburg at the same time as the petitions of nature conservation organisations. Farmers advocate that the insect topic should be treated in a holistic manner, where multiple causes are considered and a broad set of possible interventions is discussed. Similar arguments came up in the interviews with the farmers of this study. The recent scientific literature confirms various threats for insects such as loss and fragmentation of habitats through agriculture and land usage/sealing, increased mortality through climate change, invasive species, and pollution through light, noise or chemicals pollution in water and soils (Wagner 2018; Cardoso et al. 2020). However, many studies identify the modern agricultural system with its current practices as one of the main drivers for the insect biodiversity decline (Mupepele et al. 2019; Cardoso et al. 2020). To obtain stronger evidence about the drivers of the insect biodiversity loss more empirical analyses have to be carried out. These evidence-based results could promote the discourse about the type and manner of actions needed to mitigate the insect decrease. Farmers commented in the interviews that there is a contrast between urban people's thinking and acting: the urban population would demand environmental-friendly agriculture but in an unworldly and idealistic manner without being willing to change their own habits and consumer practices (e.g., paying an adequate price for sustainably produced food). A study by Witt et al. (2009) confirmed some concerns: Australian farmers also thought that urban citizens see them as 'environmental vandals'. The tension caused by different views of urban and rural people is reflected in the discourse of the 'urban-rural divide' by Witt et al. (2009). These authors revealed limited evidence of such a divide because only a small group of surveyed people can be considered sceptical regarding farmers' agricultural performance. However, it is recommended to politically promote a public debate about insect biodiversity conservation being a challenge to be addressed by the entire society.

\section{Individual-exterior dimension}

Although many farmers may feel unfairly treated by society, societal demands are powerful driving forces for more positive attitudes towards pro-environmental practices or biodiversity conservation (Kelemen et al. 2013; Mills et al. 2017; Maleksaeidi and Keshavarz 2019). Promoting insect biodiversity for instance through integrated pest management (IPM) can be achieved by giving incentives (e.g., PES, AEM), imposing regulations (e.g., prohibition of pesticides, maximum residue levels of pesticides in food production),

\footnotetext{
${ }^{1}$ https://www.bund-naturschutz.de/aktionen/volksbegehren-artenvielfalt.html.

${ }^{2}$ https://artenvielfalt-brandenburg.de/.

3 https://www.artenvielfalt-niedersachsen.jetzt/.

${ }^{4}$ http://initiativebienensummen.de.
} 
or trusting voluntary non-compensated measures via information dissemination (Lefebvre et al. 2015; Mills et al. 2017). Most interviewed farmers already perform insect-friendly measures or general pro-environmental practices because they are mandatory (e.g., EU Directive for incorporating IPM principles) or are funded by the EU (AEMs within the CAP, contractual conservation measure of the European Agricultural Fund for Rural Development). In line with our results, Lefebvre et al. (2015) and Mills et al. (2017) showed that there is a low acceptance of purely voluntary measures without external funding because it would require strong internal conviction of the necessity to promote biodiversity conservation and the ability to do so in terms of resources, expertise, and practicability. The hardest aspect to change is the underlying values and world views of farmers (Mills et al. 2017). For instance, using pesticides is proper practice for conventional farmers, and agriculture without pesticides seems unrealistic and ineffective to most of them (Lefebvre et al. 2015). There is a high risk of damages to their crops through pests and diseases, and therefore risk-averse farmers consider pesticides as a critical component of agriculture (Lamine 2011; Lefebvre et al. 2015). This practice is strongly interlinked with farmers' concerns against the prohibition of neonics (see Sect. Societal-exterior dimension).

The interviews showed that to date, the pro-environmental and insect-friendly practices are often single or isolated measures and are not well incorporated at the whole farm management or landscape level. To reach a substantial and effective promotion of biodiversity and to make agricultural systems more insect-friendly, more systemic and integrated measures at the landscape level are needed (Lefebvre et al. 2015; Landis 2017). Similar conclusions can be drawn from the innovation system theory and multi-level perspective where a broader uptake of innovations has to be achieved to change the persistent regime (Geels 2002; Sutherland et al. 2014). However, a regime shift is still far from being a reality, as described in the next paragraph.

\section{Societal-exterior dimension}

A set of lock-in effects causes farmers to stick to current agricultural practices, and the agricultural production system is still dominant (Wilson and Tisdell 2001; Lamine 2011; Meynard et al. 2018). Such lock-in effects include the interdependency between actors of the agri-food sector (providers of agro-chemicals, machinery manufacturers, advisory services, food processing companies, and farmers) (Lamine 2011), the neoliberal market system creating economic pressure (Wilson and Tisdell 2001), and the lack of value chains for alternative products (Meynard et al. 2018). The resilience and transformative capacity of farmers are relatively low, and distressed feelings are common due to the lock-in effects: farmers experience long-term stresses through competition in markets or about resources and through public distrust in agriculture and have to deal with institutional shocks (e.g., the bans of pesticides) (Meuwissen et al. 2019). The strong concerns of conventional farmers against the prohibition of neonics and their rejection of alternative options can be explained by the theory of psychological reactance (Brehm 1989). This theory explains how and why people possibly react when the portfolio of options changes or one option is eliminated. We assume that the following rule, one of a longer list by Brehm (1989), has influenced farmers' rejection: when behavioural freedom is reduced by the elimination of an option and the importance of the threatened option is high, the person will probably show resistance. As farmers perceive the use of pesticides in general and neonics and glyphosate in particular as critical for an economically well-performing farm because pests and disease damages can cause 'catastrophic' yield losses, the prohibition of neonics and 
the debate on banning glyphosate in the future are perceived as a real and enormous threat for their agricultural performance (Lefebvre et al. 2015). Scientists and policy makers should use evidence-based results to communicate the unintended negative effects of the pesticide use to farmers. For farmers it is important to understand that the current agriculture practices can weaken essential ecosystem services provided by insects while disservices and pests persist (Haan et al. 2021). There is evidence that artificially replacing ecosystem services by external inputs (fertilizer and pesticides) reinforces unsustainable land use and rises ecological and economic costs on the long run (Haan et al. 2021).

Despite these concerns, some farmers see the need to transform their individual production system (or even the whole agricultural system). However, our study showed that individual farmers can only take small-scale and less ecologically effective measures within the boundaries of their current farming system and the financial compensation system, such as establishing annual flowering field margins. On a large-scale, agricultural policies targeting transformation have to provide more incentives aimed at insect conservation at the landscape scale and resilient systems or remove barriers that hinder for instance extending crop diversity. This way, the number of farmers open for change could be further increased. Equipping farmers with more possibilities to move from production-oriented farming towards an increased focus on biodiversity, the transformation towards a resilient agricultural production system could advance. To create such a resilient system that would reduce the ecological, social, and economical negative consequences, including the consequence of recent stagnation or even a decline in crop yields (Dainese et al. 2019), and would overcome lock-in effects, a full redesign of the entire agricultural system is urgently needed and should be actively promoted (Lamine 2011; Meynard et al. 2012; Kremen and Merenlender 2018a; Haan et al. 2021). This redesign should seek to incorporate agroecological diversification practices such as IPM, intercropping, cover cropping, and crop rotation, which all indirectly enhance insect biodiversity (Hatt et al. 2016; Kremen and Merenlender 2018b; Samways et al. 2020; Lundin et al. 2021). Additionally to the production-oriented and field-based measures, it is essential to implement measures which promote biodiversity more directly by enhancing the semi-natural structure at the landscape scale (Samways et al. 2020; Lundin et al. 2021). These measures include maintaining and introducing perennial elements such as hedges, wildflower field borders and wildflower patches along roads, field trails, and water bodies. Concerns by farmers and policy-makers about lower yields due to a stronger focus on biodiversity conservation are reasonable. However, several scientific studies revealed that agroecological farming methods could maintain or even increase yields (Kremen and Merenlender 2018a; Dainese et al. 2019). However, not only innovations on the agronomic level are needed but technological, process and organisational innovations are also essential and go hand in hand to successfully create value chains for alternative crops as well as mainstream crops (Sutherland et al. 2014; Meynard et al. 2018). Additionally, redesigning agricultural landscapes is a collaborative and applicationoriented research task in which different scientific disciplines and practitioners (farmers, advisory services, policy makers, etc.) should be involved on an equal footing (Meynard et al. 2018; Kernecker et al. 2019).

\section{Critical discussion on the applied method}

Combining semantic web analysis with the four-quadrants-framework was suitable for our study because it enabled to elicit farmers' complex mental models on insect biodiversity which include individual thoughts and behaviour but also societal values and systemic 
aspects on the agricultural production system. Thus, our analysis supports to overcome disciplinary epistemological boundaries and to draw a realistic and holistic picture of what farmers think.

We identified farmers' mental models by conducting qualitative interviews with an interview guideline containing only open questions. Such an open interview technique provides a quasi-normal and trust-building conversational situation for interviewees in which they can freely express their thoughts and views (Salliou and Barnaud 2017). Previously unknown and marginal issues can be captured by this method (Patton 2019). Other interview techniques with a complex and rigorous "method corset" (e.g., network mapping, direct elicitation of mental models) are sometimes perceived as uncomfortable and exhausting by interviewees, especially farmers. Due to this open interview technique, we elicited farmers' cognitive structures not directly during the interview situation but afterwards in the scientific analysis. This procedure depends on researcher's capability of interpreting qualitative data (Vanwindekens et al. 2013). To meet the quality criteria such as transparency and validity, high expertise and experience in conducting qualitative social research is required (Salliou and Barnaud 2017; Patton 2019). Co-constructing mental models with interviewees provides the opportunity that interviewees can validate and reflect their own mental models afterwards (Hulst et al. 2020). However, in our methodological procedure it was not possible to request farmers' feedback on their web diagrams. The indirect procedure of revealing mental models only allows to look at the frequency of occurrence of concepts and relationships in grouped mental maps but does not allow to weigh the extent of causal influences of concepts and relationships like in the direct mapping methods (Vanwindekens et al. 2013). Although our analytical results are valid for the two case study areas (landscape labs), due to the limited sample size (23 interviews), we cannot conclude if the identified farmers' mental models are representative for German farmers in general. For instance it was not possible to make statistically reliable statements on the influence of gender, age, and work experience. Results of our explorative and qualitative study could be used to set up a survey to conduct a quantitative analysis at larger scale with conventional and organic farmers which would enhance the scope of our conclusions. In this context, it would be interesting to apply a cluster analysis based on the survey data for identifying whether conventional farmers and organic farmers differ in their mental models.

\section{Conclusions}

This study revealed for the first time in-depth insights into farmers' thinking about insect biodiversity, biodiversity loss and how farmers contextualise perceptions and attitudes to their agricultural practice and the agricultural production system. Methodologically, we used mental model elicitation by web diagrams, which supports not only the identification of overlaps in farmers' mental models but also paves the way for building shared views and solutions as a requirement for the joint implementation task of biodiversity enhancing agricultural practices and systems (cf. van Hulst et al. 2020). Thus, our results on farmers' perceptions and attitudes are an important basis for the redesign of the current farming system at a local level in our case study regions.

Drawing conclusions from our results for a successful collaboration with farmers in research projects about biodiversity conservation at the landscape scale, we recommend to establish landscape labs that enable: (1) actively involving farmers with their knowledge, expertise, and concerns in a co-design process; (2) to discuss mental models and set 
up joint transformation pathways; (3) to co-develop locally suitable measures that lead to ecologically effective and broadly accepted solutions; (4) to co-experiment the practicability of measures and economically and ecologically assess them at local scale (Meynard et al. 2012; Campellone et al. 2018). On the one hand, in co-design processes at the landscape level it is often challenging to bring together diverging interests, values, and farming systems. On the other hand, co-design and applying a landscape lab approach promotes mutual learning through collective actions, building up farmers networks, and social capital (Reed 2008; Steingröver et al. 2010; Campellone et al. 2018)”.

The farmers' mental models revealed that one suitable solution at the case study level could be to create regional value chains for insect-friendly crops such as legumes or flowering energy crops. However, regional values chains can hardly be established by farmers but need joint efforts by regional innovation initiatives in which farmers, scientists, agricultural advisory services, processing and trading businesses, policy makers are involved. Above all, it takes a long time to create viable and sustainable regional value chains. In the short term, transdisciplinary research projects using a landscape lab approach can be an interim solution to finance insect-friendly measures.

While recognizing that a sustainable redesign of farming systems has to be performed at the local level first because there is no one fits all solution for the diversity of real-world biodiversity problems in the agricultural landscape, efforts also have to be done all over the globe (Samways et al. 2020). Transformation efforts at the local or niche level can demonstrate new pathways for a shift of regime levels and be lighthouse projects by testing which forms of collaboration work well, which practices are acceptable and where adaptations are still needed.

Supplementary Information The online version contains supplementary material available at https://doi. org/10.1007/s10531-021-02235-2.

Acknowledgements We would like to thank all interview partners, the project partners, and the anonymous reviewers of the manuscript.

Author contributions Conception and design of the work: MB, FZ, RS; Acquisition: RS; Data collection and interpretation: MB FZ RS, ABa, ABo, PS; Draft of manuscript: MB, FZ; Revision of manuscript: RS, $\mathrm{ABa}, \mathrm{ABo}, \mathrm{PS}$; Approved for publication: MB FZ RS, ABa, ABo, PS.

Funding Funding from the Federal Ministry of Food and Agriculture, Germany (BMEL) has supported this study (Funding Code 22012218). Open Access funding enabled and organized by Projekt DEAL.

Data Availability Confidential interview data.

\section{Declarations}

Conflict of interest The authors declare that they have no competing interests.

Open Access This article is licensed under a Creative Commons Attribution 4.0 International License, which permits use, sharing, adaptation, distribution and reproduction in any medium or format, as long as you give appropriate credit to the original author(s) and the source, provide a link to the Creative Commons licence, and indicate if changes were made. The images or other third party material in this article are included in the article's Creative Commons licence, unless indicated otherwise in a credit line to the material. If material is not included in the article's Creative Commons licence and your intended use is not permitted by statutory regulation or exceeds the permitted use, you will need to obtain permission directly from the copyright holder. To view a copy of this licence, visit http://creativecommons.org/licenses/by/4.0/. 


\section{References}

Bardenhagen CJ, Howard PH, Gray SA (2020) Farmer mental models of biological pest control: associations with adoption of conservation practices in Blueberry and Cherry Orchards. Front Sustain Food Syst 4:54. https://doi.org/10.3389/fsufs.2020.00054

Bardsley DK, Palazzo E, Stringer R (2019) What should we conserve? Farmer narratives on biodiversity values in the McLaren Vale, South Australia. Land Use Policy 83: 594-605

Benard M, de Cock Buning T (2013) Exploring the potential of dutch pig farmers and urban-citizens to learn through frame reflection. J Agric Environ Ethics 26:1015-1036. https://doi.org/10.1007/ s10806-013-9438-y

Berkes F (2017) Environmental governance for the Anthropocene? Social-ecological systems, resilience, and collaborative learning. Sustainability 9:1232. https://doi.org/10.3390/su9071232

Biggs D, Abel N, Knight AT et al (2011) The implementation crisis in conservation planning: could "mental models" help?: Mental models in conservation planning. Conserv Lett 4:169-183. https://doi.org/10. 1111/j.1755-263X.2011.00170.x

Brehm J (1989) Psychological reactance: theory and applications. Adv Consum Res 16:72-75

Burton RJF, Wilson GA (2006) Injecting social psychology theory into conceptualisations of agricultural agency: Towards a post-productivist farmer self-identity? J Rural Stud 22:95-115. https://doi.org/10. 1016/j.jrurstud.2005.07.004

Busse M, Heitepriem N, Siebert R (2019) The acceptability of land pools for the sustainable revalorisation of wetland meadows in the Spreewald region,\&nbsp;Germany. Sustainability 11:4056. https://doi.org/ 10.3390/su11154056

Campellone RM, Chouinard KM, Fisichelli NA et al (2018) The iCASS platform: nine principles for landscape conservation design. Landsc Urban Plan 176:64-74. https://doi.org/10.1016/j.landurbplan.2018. 04.008

Cardoso P, Barton PS, Birkhofer K et al (2020) Scientists' warning to humanity on insect extinctions. Biol Conserv 242:108426. https://doi.org/10.1016/j.biocon.2020.108426

Dainese M, Martin EA, Aizen MA et al (2019) A global synthesis reveals biodiversity-mediated benefits for crop production. Sci Adv 5:eaax0121. https://doi.org/10.1126/sciadv.aax0121

Esbjörn-Hargens S, Zimmerman ME (2009) Integral ecology: uniting multiple perspectives on the natural world, 1st\&nbsp;edn. Integral Books, Boston

Geels FW (2002) Technological transitions as evolutionary reconfiguration processes: a multi-level perspective and a case-study. Res Policy 31:1257-1274. https://doi.org/10.1016/S0048-7333(02)00062-8

Gordon I, Calatayud P-A, Le Gall P, Garnery L (2019) We are losing the little things that run the world. UN Environ Forsight Brief 1-9

Grass I, Albrecht J, Jauker F et al (2016) Much more than bees-wildflower plantings support highly diverse flower-visitor communities from complex to structurally simple agricultural landscapes. Agric Ecosyst Environ 225:45-53. https://doi.org/10.1016/j.agee.2016.04.001

Haan NL, Iuliano BG, Gratton C, Landis DA (2021) Designing agricultural landscapes for arthropod-based ecosystem services in North America. In: Advances in Ecological Research. Elsevier, pp\&nbsp;191-250

Hall DM, Martins DJ (2020) Human dimensions of insect pollinator conservation. Curr Opin Insect Sci 38:107-114. https://doi.org/10.1016/j.cois.2020.04.001

Hatt S, Artru S, Brédart D et al (2016) Towards sustainable food systems: the concept of agroecology and how it questions current research practices. A review. Biotechnol Agron Soc Environ 20:215-224

Hevia V, García-Llorente M, Martínez-Sastre R et al (2020) Do farmers care about pollinators? A cross-site comparison of farmers' perceptions, knowledge, and management practices for pollinator-dependent crops. Int J Agric Sustain. https://doi.org/10.1080/14735903.2020.1807892

Isaacs R, Tuell J, Fiedler A et al (2009) Maximizing arthropod-mediated ecosystem services in agricultural landscapes: the role of native plants. Front Ecol Environ 7:196-203. https://doi.org/10.1890/080035

Jankielsohn A (2018) The importance of insects in agricultural ecosystems. Adv Entomol 06:62-73. https:// doi.org/10.4236/ae.2018.62006

Kelemen E, Nguyen G, Gomiero T et al (2013) Farmers' perceptions of biodiversity: lessons from a discourse-based deliberative valuation study. Land Use Policy 35:318-328. https://doi.org/10.1016/j. landusepol.2013.06.005

Kernecker M, Busse M, Zscheischler J (2019) Avert collapse of research co-production systems. Nature 573:495-495. https://doi.org/10.1038/d41586-019-02860-6

Kremen C, Merenlender AM (2018a) Landscapes that work for biodiversity and people. Science 362:eaau6020. https://doi.org/10.1126/science.aau6020 
Kremen C, Merenlender AM (2018b) Landscapes that work for biodiversity and people. Science 362:eaau6020. https://doi.org/10.1126/science.aau6020

Kuckartz U (2014) Qualitative text analysis: a guide to methods, practice and using software—sage research methods. SAGE Publications Ltd, London

Lamine C (2011) Transition pathways towards a robust ecologization of agriculture and the need for system redesign. Cases from organic farming and IPM. J Rural Stud 27:209-219. https://doi.org/10.1016/j. jrurstud.2011.02.001

Landis DA (2017) Designing agricultural landscapes for biodiversity-based ecosystem services. Basic Appl Ecol 18:1-12. https://doi.org/10.1016/j.baae.2016.07.005

Lange A, Siebert R, Barkmann T (2016) Incrementality and regional bridging: instruments for promoting stakeholder participation in land use management in Northern Germany. Soc Nat Resour 29:868-879. https://doi.org/10.1080/08941920.2015.1122135

Leandro C, Jay-Robert P (2019) Perceptions and representations of animal diversity: where did the insects go? Biol Conserv 237:400-408. https://doi.org/10.1016/j.biocon.2019.07.031

Lefebvre M, Langrell SRH, Gomez-y-Paloma S (2015) Incentives and policies for integrated pest management in Europe: a review. Agron Sustain Dev 35:27-45. https://doi.org/10.1007/ s13593-014-0237-2

Lundin O, Rundlöf M, Jonsson M et al (2021) Integrated pest and pollinator management-expanding the concept. Front Ecol Environ. https://doi.org/10.1002/fee.2325

Maleksaeidi H, Keshavarz M (2019) What influences farmers' intentions to conserve on-farm biodiversity? An application of the theory of planned behavior in fars province, Iran. Glob Ecol Conserv 20:e00698. https://doi.org/10.1016/j.gecco.2019.e00698

Martínez-Sastre R, García D, Miñarro M, Martín-López B (2020) Farmers perceptions and knowledge of natural enemies as providers of biological control in cider apple orchards. J Environ Manage 266:110589. https://doi.org/10.1016/j.jenvman.2020.110589

Mayring P (2014) Qualitative content analysis: theoretical foundation, basic procedures and software solution. Available online: https://www.ssoar.info/ssoar/handle/document/39517. Accessed 25 July 2019

Mero-Jaffe I (2011) Is that what i said? Interview transcript approval by participants: an aspect of ethics in qualitative research. Int J Qual Methods 10:231-247. https://doi.org/10.1177/160940691101000 304

Meuwissen MPM, Feindt PH, Spiegel A et al (2019) A framework to assess the resilience of farming systems. Agric Syst 176:102656. https://doi.org/10.1016/j.agsy.2019.102656

Meynard J-M, Dedieu B, Bram Bos AP (2012) Re-design and co-design of farming systems. An overview of methods and practices. Springer Netherlands

Meynard J-M, Charrier F, Fares M et al (2018) Socio-technical lock-in hinders crop diversification in France. Agron Sustain Dev 38:54. https://doi.org/10.1007/s13593-018-0535-1

Mills J, Gaskell P, Ingram J et al (2017) Engaging farmers in environmental management through a better understanding of behaviour. Agric Hum Values 34:283-299. https://doi.org/10.1007/ s10460-016-9705-4

Moon K, Blackman DA, Adams VM et al (2019) Expanding the role of social science in conservation through an engagement with philosophy, methodology, and methods. Methods Ecol Evol 10:294-302. https://doi.org/10.1111/2041-210X.13126

Mupepele A-C, Böhning-Gaese K, Lakner S et al (2019) Insect conservation in agricultural landscapes: an outlook for policy-relevant research. GAIA Ecol Perspect Sci Soc 28:342-347. https://doi.org/ 10.14512/gaia.28.4.5

Patton MQ (2019) Qualitative Research and Evaluation Methods Integrating Theory and Practice, 4th edn. SAGE Publications Ltd, Thousand Oaks

Potts SG, Woodcock BA, Roberts SPM et al (2009) Enhancing pollinator biodiversity in intensive grasslands. J Appl Ecol 46:369-379. https://doi.org/10.1111/j.1365-2664.2009.01609.x

Prager K, Curfs M (2016) Using mental models to understand soil management. Soil Use Manag 32:3644. https://doi.org/10.1111/sum.12244

Reed MS (2008) Stakeholder participation for environmental management: a literature review. Biol Conserv 141:2417-2431. https://doi.org/10.1016/j.biocon.2008.07.014

Reed MS, Graves A, Dandy N et al (2009) Who's in and why? A typology of stakeholder analysis methods for natural resource management. J Environ Manage 90:1933-1949. https://doi.org/10.1016/j. jenvman.2009.01.001

Salliou N, Barnaud C (2017) Landscape and biodiversity as new resources for agro-ecology? Insights from farmers perspectives. Ecol Soc 22:art16. https://doi.org/10.5751/ES-09249-220216 
Samways MJ, Barton PS, Birkhofer K et al (2020) Solutions for humanity on how to conserve insects. Biol Conserv 242:108427. https://doi.org/10.1016/j.biocon.2020.108427

Schowalter TD, Noriega JA, Tscharntke T (2018) Insect effects on ecosystem services-introduction. Basic Appl Ecol 26:1-7. https://doi.org/10.1016/j.baae.2017.09.011

Steingröver EG, Geertsema W, van Wingerden WKRE (2010) Designing agricultural landscapes for natural pest control: a transdisciplinary approach in the Hoeksche Waard (The Netherlands). Landsc Ecol 25:825-838. https://doi.org/10.1007/s10980-010-9489-7

Sutherland L-A, Darnhofer I, Wilson G, Zagata L (2014) Transition pathways towards sustainability in agriculture: case studies from Europe. CABI, Wallingford

Tarakini G, Chemura A, Musundire R (2020) Farmers knowledge and attitudes toward pollination and bees in a maize-producing region of Zimbabwe: implications for pollinator conservation. Trop Conserv Sci 13:194008292091853. https://doi.org/10.1177/1940082920918534

van Hulst F, Ellis R, Prager K, Msika J (2020) Using co-constructed mental models to understand stakeholder perspectives on agro-ecology. Int J Agric Sustain 18:172-195. https://doi.org/10.1080/14735 903.2020.1743553

Vanwindekens FM, Stilmant D, Baret PV (2013) Development of a broadened cognitive mapping approach for analysing systems of practices in social-ecological systems. Ecol Model 250:352-362. https://doi. org/10.1016/j.ecolmodel.2012.11.023

Wagner D (2018) Trends in biodiversity: insects. In: Reference module in earth systems and environmental sciences. Elsevier

Warren CR, Burton R, Buchanan O, Birnie RV (2016) Limited adoption of short rotation coppice: the role of farmers socio-cultural identity in influencing practice. J Rural Stud 45:175-183. https://doi.org/10. 1016/j.jrurstud.2016.03.017

Wensing J, Carraresi L, Bröring S (2019) Do pro-environmental values, beliefs and norms drive farmers' interest in novel practices fostering the Bioeconomy? J Environ Manage 232:858-867. https://doi.org/ 10.1016/j.jenvman.2018.11.114

Wilson C, Tisdell C (2001) Why farmers continue to use pesticides despite environmental, health and sustainability costs. Ecol Econ 39:449-462. https://doi.org/10.1016/S0921-8009(01)00238-5

Witt GB, Witt KJ, Carter RW, Gordon A (2009) Exploring the city-bush divide: what do urban people really think of farmers and rural land management? Australas J Environ Manag 16:168-180. https://doi.org/ $10.1080 / 14486563.2009 .9725233$

Witzel A (2000) The problem-centered interview. Forum Qual Sozialforschung Forum Qual Soc Res 1:1. https://doi.org/10.17169/fqs-1.1.1132

Wood MD, Bostrom A, Bridges T, Linkov I (2012) Cognitive mapping tools: review and risk management needs: cognitive mapping tools. Risk Anal 32:1333-1348. https://doi.org/10.1111/j.1539-6924.2011. 01767.x

Zscheischler J, Rogga S, Busse M (2017) The adoption and implementation of transdisciplinaryresearch in the field of land-use science—a comparative case study. Sustainability 9:1926. https://doi.org/10.3390/ su9111926

Zylstra M, Esler K, Knight A, Le Grange L (2019) Integrating multiple perspectives on the human-nature relationship: a reply to Fletcher 2017. J Environ Educ 50:1-10. https://doi.org/10.1080/00958964. 2018.1497582

Publisher's Note Springer Nature remains neutral with regard to jurisdictional claims in published maps and institutional affiliations.

\section{Authors and Affiliations}

\section{Maria Busse $^{1}$ D $\cdot$ Felix Zoll ${ }^{1} \cdot$ Rosemarie Siebert $^{1} \cdot$ Annette Bartels $^{2}$. Anke Bokelmann ${ }^{2} \cdot$ Phillipp Scharschmidt ${ }^{1}$}

1 Leibniz Centre for Agricultural Landscape Research (ZALF), Eberswalder Strasse 84, 15374 Muencheberg, Germany

2 Lower Saxony Chamber of Agriculture, Mars-la-Tour-Strasse 1-13, 26121 Oldenburg, Germany 